Corinna, et al/ Jurnal Ekonomi Syariah Teori dan Terapan Vol. 6 No. 2 Februari 2019: 319-330; POLA PERILAKU KONSUMSI GENERASI MILLENIAL TERHADAP PRODUK FASHION PERSPEKTIF MONZER KAHF : STUDI KASUS MAHASISWI UNIVERSITAS AIRLANGGA

\title{
POLA PERILAKU KONSUMSI GENERASI MILLENIAL TERHADAP PRODUK FASHION PERSPEKTIF MONZER KAHF : STUDI KASUS MAHASISWI UNIVERSITAS AIRLANGGA
}

\author{
Arlinda Nidia Corinna \\ Departemen Ekonomi Syariah-Fakultas Ekonomi dan Bisnis-Universitas Airlangga \\ Email: arlinda.nidia@gmail.com \\ Eko Fajar Cahyono \\ Departemen Ekonomi Syariah-Fakultas Ekonomi dan Bisnis-Universitas Airlangga \\ Email: ekofajarc@feb.unair.ac.id
}

\begin{abstract}
:
This study examines how consumption patterns of millennial generation towards fashion products based on Monzer Kahf's perspective, especially female students from Airlangga University. The research method uses a descriptive case study method. Data collection in this study was carried out by an in-depth interview method and the subjects of the study were asked the questions immediately. The analysis technique carried out in this study is by reducing data, presenting data both through the results of interviews and observations of researchers towards the informants, then proceed with drawing conclusions. The results of the study show that Airlangga University students have applied the principles of Islamic consumption from Monzer Kahf's perspective as a pattern of consumption behavior towards fashion products. Millennials in Indonesia, especially university students, are principled by consumption in accordance with Islamic teachings by promoting consumption rationalism, consumption balance, Islamic goods and consumption ethics.
\end{abstract}

Keywords: Consumption, Islamic consumption, Millenials, Fashion Product, Rationalism, Consumption Balance, Islamic Goods.

\section{PENDAHULUAN}

\section{Latar Belakang Masalah}

Konsumsi sangat berpengaruh terhadap stabilitas perekonomian. Semakin tinggi tingkat konsumsi, semakin tinggi pula perubahan kegiatan ekonomi. Kebutuhan hidup manusia selalu berkembang sejalan dengan tuntutan zaman. Gaya hidup masyarakat saat ini sudah mengikuti gaya hidup negaranegara maju, gaya hidup yang hedonis menyebabkan masyarakat berperilaku konsumtif. Arus globalisasi telah membawa pengaruh modernisasi yang sangat besar terhadap perubahan dalam berbagai hal, mulai dari teknologi informasi dan telekomunikasi hingga hal terkecil dalam sektor kehidupan ini, termasuk fashion salah satunya. Indonesia dengan berpenduduk muslim terbanyak di dunia yang menyumbang setidaknya $10,6 \%$ dari total pemeluk agama islam di dunia, menjadikan Indonesia memiliki potensi untuk menerapkan pola perilaku yang sesuai dengan norma-norma syariat. Pesatnya perkembangan fashion di Indonesia berhasil mendapat pengakuan oleh negara-negara besar.

Yang perlu kita cermati adalah hal ini membuat wanita muslim bisa memilih gaya fashion sesuai keinginannya, namun, di sisi lain, terdapat beberapa problema bagi wanita muslim terkait hal ini. Hal ini dikhawatirkan terdapat pergeseran norma-norma syariat bagi wanita muslim. Atau bisa jadi, pergeseran nilai dan norma

1) Jurnal ini merupakan bagian dari skripsi Arlinda Nidia Corinna, NIM: 041411431104 , yang diuji pada tanggal 15 Januari 2019. 
Corinna, et al/ Jurnal Ekonomi Syariah Teori dan Terapan Vol. 6 No. 2 Februari 2019: 319-330; POLA PERILAKU KONSUMSI GENERASI MILLENIAL TERHADAP PRODUK FASHION PERSPEKTIF MONZER KAHF : STUDI KASUS MAHASISWI UNIVERSITAS AIRLANGGA

disini justru menjadi terobosan masyarakat yang dinamis dalam memandang fashion.

"Wahai anak cucu Adam, pakailah pakaianmu yang baguspada setiap (memasuki) mesjid, makan dan minumlah, tetapi jangan berlebihan. Sungguh, Allah tidak menyukai orang yang berlebihlebihan." Ibnu Abbas berkata bahwa makna yang dimaksud ialah makanlah sesukamu dan berpakaianlah sesukamu selagi engkau hindari dua perkara yaitu berlebih-lebihan dan sombong. Allah menghalalkan makan dan minum selagi dilakukan dengan tidak berlebih-lebihan dan tidak untuk kesombongan.

Generasi Milenial menyumbang 27\% populasi dunia (yaitu 2 miliar orang), dengan sekitar 58\% tinggal di Asia (Sillman et al., 2016). Angka-angka ini menyoroti dampak Millenial saat ini dan masa depan pada ekonomi dunia, sehingga dapat disimpulkan bahwa mereka akan menjadi kelompok konsumen paling kuat (Farris ef al., 2012 Milenial adalah orang-orang yang lahir antara awal tahun 1980an dan awal 2000an (Pew Research Center, 2016). Mereka mewakili generasi muda yang terlahir di dunia global yang memiliki interdependensi dan keterlibatan global (Pendergast, 2007).

Menyangkut kebutuhan dan konsumsi, maka, dalam pemenuhannya dapat dikelompokkan dalam tiga tingkatan (Abdul Mannan. 1997), yaitu: daruriyyat (kebutuhan minimum), hajiyyat (kebutuhan yang mencukupi) dan tahsiniyat (kebutuhan yang menyenangkan). Dalam ekonomi islam, semua aktivitas manusia yang bertujuan untuk kebaikan merupakan ibadah, termasuk konsumsi. Didasarkan atas penjelasan di atas maka konsumsi dalam ekonomi islam dapat diartikan sebagai pemenuhan kebutuhan baik jasmani maupun rohani sehingga mampu memaksimalkan fungsi kemanusiaannya sebagai hamba Allah SWT untuk mendapatkan kesejahteraan dan kebahagiaan di dunia dan di akhirat (falah).

Menurut Yusuf Qardhawi (1997), dalam melakukan konsumsi, maka konsumsi tersebut harus dilakukan pada barang yang halal dan baik (halalan toyibban) dengan cara berhemat (saving), berinfak (mashlahat) serta menjauhi judi, khamar, gharar dan spekulasi. Ini berarti bahwa prilaku konsumsi yang dilakukan manusia (terutama Muslim) harus menjauhi kemegahan, kemewahan, kemubaziran dan menghindari hutang

Maka dari itu, hal ini semakin membuat peneliti untuk membuat judul skripsi "Pola Perilaku Konsumsi Muslimah Generasi Milenial terhadap Produk Fashion Perspektif Monzer Kahf: Studi Kasus Mahasiswi Universitas Airlangga"

\section{Rumusan Masalah}

Berdasarkan latar belakang yang dipaparkan tersebut, rumusan masalah dalam penelitian ini adalah: Bagaimana pola perilaku konsumsi muslimah generasi milenial khususnya mahasiswi Universitas Airlangga terhadap produk fashion perspektif Monzer Kahf? 
Corinna, et al/ Jurnal Ekonomi Syariah Teori dan Terapan Vol. 6 No. 2 Februari 2019: 319-330; POLA PERILAKU KONSUMSI GENERASI MILLENIAL TERHADAP PRODUK FASHION PERSPEKTIF MONZER KAHF : STUDI KASUS MAHASISWI UNIVERSITAS AIRLANGGA

\section{LANDASAN TEORI}

\section{Teori Konsumsi Dusenberry}

Dalam teorinya, Dusenberry menggunakan dua asumsi yaitu:

a. Selera sebuah rumah tangga atas barang konsumsi adalah interdependen. Artinya pengeluaran konsumsi rumah tangga dipengaruhi oleh pengeluaran yang dilakukan oleh orang sekitarnya.

b. Pengeluaran konsumsi adalah irreversible. Artinya pola pengeluaran seseorang pada saat penghasilan naik berbeda dengan pola pengeluaran pada saat penghasilan mengalami penurunan.

\section{Preferensi Konsumen}

Menurut Rianto dan Amalia (2010), dalam membangun suatu teori perilaku konsumen dalam kaitannya dengan perilaku konsumen untuk memaksimumkan kepuasan digunakan empat prinsip pilihan rasional, yaitu: (a) Kelengkapan, prinsip ini mengatakan bahwa setiap individu selalu dapat menentukan keadaan mana yang lebih disukainya di antara dua keadaan. (b) Transivitas, prinsip ini menerangkan mengenai konsistensi seseorang dalam menentukan dan memutuskan pilihannya bila dihadapkan oleh beberapa alternatif pilihan produk. (c) Kesinambungan, prinsip ini menjelaskan bahwa jika seorang individu mengatakan "produk A lebih disukai daripada produk B", maka setiap keadaan yang mendekati produk A pasti juga akan lebih disukai daripada produk B. Jadi, ada suatu kekonsistenan seorang konsumen dalam memilih suatu produk yang akan dikonsumsinya. (d) Lebih
Banyak Lebih Baik, prinsip ini menjelaskan bahwa jumlah kepuasan akan meningkat, jika individu mengonsumsi lebih banyak barang atau produk tersebut.

\section{Memaximalkan Utility}

Di dalam teori ekonomi kepuasan atau yang diperoleh seseorang dari mengkonsumsikan barang-barang disebut nilai guna atau utility. Apabila kepuasan itu semakin tinggi maka makin tinggilah nilai gunanya atau utilitinya. Dalam konteks ekonomi, utilitas diartikan sebagai kegunaan barang yang dirasakan oleh seorang konsumen dalam mengonsumsi suatu barang. Kegunaan ini bisa dirasakan sebagai rasa tertolong dari kesulitan karena telah mengonsumsi suatu barang (Rachmawaty, 2011).

Hukum nilai guna marjinal yang semakin menurun, menyatakan bahwa tambahan nilai guna yang diperoleh seseorang dari mengkonsumsikan suatu barang akan menjadi semakin sedikit apabila orang tersebut terus menerus menambah konsumsinya ke atas barang tersebut. Pada akhirnya tambahan nilai guna akan menjadi negatif yaitu apabila konsumsi ke atas barang tersebut ditambah satu unit lagi, maka nilai guna total akan menjadi semakin sedikit.

Teori nilai guna dapat pula menerangkan tentang wujudnya kelebihan kepuasan yang dinikmati oleh para konsumen. Kelebihan kepuasan ini, dalam analisis ekonomi, dikenal sebagai surplus konsumen.

\section{Konsumsi Islam}

Qardhawi menguraikan beberapa 
Corinna, et al/ Jurnal Ekonomi Syariah Teori dan Terapan Vol. 6 No. 2 Februari 2019: 319-330; POLA PERILAKU KONSUMSI GENERASI MILLENIAL TERHADAP PRODUK FASHION PERSPEKTIF MONZER KAHF : STUDI KASUS MAHASISWI UNIVERSITAS AIRLANGGA

prinsip perilaku konsumsi dalam Islam sebagai berikut:

a) Dasar pemikiran pola konsumsi dalam Islam adalah hendak mengurangi kelebihan keinginan biologis yang tumbuh dari faktor-faktor psikis buatan dengan maksud membebaskan energi manusia untuk tujuan-tujuan spiritual.

b) Anjuran-anjuran Islam mengenai perilaku konsumsi dituntun oleh prinsip keadilan, prinsip kebersihan, prinsip kesederhanaan, prinsip kemurahan hati dan prinsip moralitas.

c) Kunci untuk memahami perilaku konsumsi dalam Islam tidak cukup dengan hanya mengetahui hal-hal terlarang, tetapi sekaligus harus dengan menyadari konsep dinamik tentang sikap moderat dalam pola konsumsi yang dituntun oleh sikap yang mementingkan bersama konsumen muslim yang lain.

Dari hal-hal yang diuraikan diatas dapat dijelaskan bahwa prinsip perilaku konsumsi yang dapat memberikan kepuasan kepada konsumen menurut Islam adalah barang-barang yang dikonsumsi haruslah halal dan suci menurut syariat. Dalam hal perilaku atau gaya harus pula dalam batas wajar dalam arti tidak berlebih-lebihan (isyrāf) atau boros (tabīir) meskipun seorang konsumen tergolong hidup kaya atau mampu.

\section{Muslimah dalam Berkonsumsi}

Tumbuh suburnya budaya konsumen, tidak sekedar memandang konsumsi yang berasal dari produksi tanpa mengakibatkan adanya problematika dalam masyarakat. Salah satu masalahnya adalah karena yang dikonsumsi adalah makna yang dilekatkan pada barang itu, sehingga kita tidak pernah mampu memenuhi kebutuhan kita karena merasa tidak pernah terpuaskan. Masyarakat kita dirusak oleh tatanan masyarakat konsumsi, yang merupakan tatanan dari manipulasi tanda (Baudrillard, 2011:16).

Konsumerisme dan fashion

merupakan pengkodean atau penyimbolan yang mensugesti masyarakat, memeliki kemungkinankemungkinan terburuk seperti dapat merusak suatu sistem tatanan yang ada dalam masyarakat.

Sebagai contoh, salah satu model yang diikuti oleh kalangan perempuan saat ini adalah Dian Pelangi, seorang desainer muda asal Jakarta, bersama rekannya, Ria Miranda, berinisiatif membentuk sebuah komunitas hijab yang berfokus pada syiar melalui cara-cara yang lebih modern, bergaya khas anak muda, namun tetap patuh pada kaidah.

\section{Generasi Millenial}

Di Indonesia studi dan kajian tentang generasi millennial belum banyak dilakukan, padahal secara jumlah populasi penduduk Indonesia yang berusia antara 15-34 tahun saat ini sangat besar, $34,45 \%$. hasil riset yang dirilis oleh Pew Researh Center menjelaskan keunikan generasi millennial dibanding generasi-generasi sebelumnya. Kaum millennial seringkali disebut sebagai pencetak tren. Apa yang mereka beli dan 
Corinna, et al/ Jurnal Ekonomi Syariah Teori dan Terapan Vol. 6 No. 2 Februari 2019: 319-330; POLA PERILAKU KONSUMSI GENERASI MILLENIAL TERHADAP PRODUK FASHION PERSPEKTIF MONZER KAHF : STUDI KASUS MAHASISWI UNIVERSITAS AIRLANGGA

gunakan dapat dipastikan merupakan produk terbaru, baik itu dalam hal gadget, gaya hidup, maupun mode. (website resmi Alvara Research Center).

Secara garis besar, hasil riset menunjukkan adanya perubahan perilaku yang sangat signifikan dari cara konsumen menghabiskan vangnya. Ini akan menjadi tantangan besar bagi industri di Indonesia. Riset yang dilakukan menunjukkan bahwa konsumen semakin cerdas dalam menentukan pilihan. Hidup ditengah-tengah teknologi yang memberikan kemudahan, generasi millennials diprediksi akan banyak melakukan konsumsi. Namun ternyata perilaku millennials cenderung malah menjadi konservatif. Meski mudah untuk membeli sesuatu mereka lebih banyak kritis dalam membeli sesuatu sebab dalam pandangan millennials yang berpendidikan nilai dan fungsi adalah yang utama. Itu sebabnya millennials kerap dipandang sebagai anti konsumerisme. Para millennials akan lebih selektif dalam mengkonsumsi merek. Selain sekuat tenaga untuk mencari harga termurah mereka juga akan loyal pada sebuah merek ketika diketahui bahwa merek tersebut benar-benar otentik.

\section{Konsumsi Perpektif Monzer Kahf}

Dalam bukunya "The Islamic Economy" Kahf mendefenisikan Islam secara ekonometris. ia melihat bahwa kepustakaan ekonomi Islam selama ini dinilainya sebagai gambaran deskriptif mengenai sistem ekonomi Islam. Kahf mencoba mengambarkan bagaimana suatu perekonomian itu dapat bekerja, berdasarkan variabel-variabel pokok yang ditentukan. Variabel tersebut meliputi rasionalisme konsumsi islam , keseimbangan konsumsi, konsep islam tentang barang, dan etika konsumsi islam. Rasionalisme Islam adalah salah satu istilah yang paling bebas digunakan dalam ekonomi, karena segala sesuatu dapat dirasionalisasikan sekali kita mengacuhnya kepada beberapa perangkat aksioma yang relevan (Nur Chamid, 2011: 388-389). Kahf menyebutkan bahwasanya perilaku ekonomi manusia di bawah budaya Islam di dominasi oleh 3 prinsip:

1. Kepercayaan akan hari akhir

2. Konsep Kesuksesan, dalam Islam kesuksesan itu dipandang dari segi "taat kepada Allah" dan pelarangan akan penimbunan harta.

3. Konsep Kekayaan, harta adalah karunia Allah, oleh karena itu harta harus digunakan untuk kepentingan dan pemenuhan kebutuhan manusia.

\section{METODOLOGI PENELITIAN}

\section{Pendekatan Penelitian}

Pendekatan dalam penelitian ini menggunakan metode kualitatif deskriptif. Penelitian kualitatif adalah penelitian yang menggunakan latar alamiah dengan maksud menafsirkan fenomena yang terjadi dan dilakukan dengan jalan melibatkan berbagai metode yang ada ( Lincoln , 1987).

Landasan berpikir dari penelitian kualitatif ini adalah menggunakan studi kasus eksploratif. Menurut Yin (2009:1), 
studi kasus adalah suatu strategi yang dipakai apabila ada pokok pertanyaan yang ditanyakan dengan kata bagaimana atau mengapa. Studi kasus merupakan serangkaian kegiatan yang dilakukan dengan mendalam dan terperinci mengenai suatu peristiwa.

Penelitian ini berdasarkan sifatnya adalah penelitian deskriptif. Sugiyono (2005) menyatakan bahwa metode deskriptif adalah suatu metode yang digunakan untuk menggambarkan atau menganalisis suatu hasil penelitian tetapi tidak digunakan untuk membuat kesimpulan yang lebih luas.

\section{Ruang Lingkup Penelitian}

Ruang lingkup penelitian ini terkait dengan rumusan masalah yang telah disinggung di bab sebelumnya, yaitu bagaimana pola perilaku konsumsi generasi milenial muslimah dari Universitas Airlangga terhadap produk fashion, yang meliputi hijab, pakaian, berhias, dan aksesoris lainnya menurut teori konsumsi yang telah dibuat oleh Monzer Kahf. Subjek penelitian ini adalah mahasiswi Universitas Airlangga dengan berbagai macam latar belakang dan kegiatan sehari-hari.

\section{Jenis dan Sumber Data}

Data yang digunakan dalam penelitian ini adalah data primer dan data sekunder.

1. Data primer adalah data yang diperoleh peneliti dari sumber asli (langsung dari informan) yang memiliki informasi atau data tersebut. Data primer diperoleh dari wawancara dan observasi secara langsung pada mahasiswi Universitas Airlangga yang dipilih secara acak oleh peneliti. Kriteria informan yang akan diwawancari yaitu :

a) Mahasiswi Universitas Airlangga:

1) Mahasiswi yang beragama islam.

2) Mahasiswi yang memiliki pendapatan , boleh bersumber dari orang tua ataupun dari dirinya sendiri

3) Mahasiswi yang melakukan kegiatan konsumsi produk fashion.

b) Orang terdekat dari Mahasiswi Universitas Airlangga sebagai Triangulasi Data

1) Mengenal informan utama yaitu mahasiswi Universitas Airlangga

2) Sering berinteraksi dengan informan utama

2. Data sekunder adalah data yang diambil dari sumber kedua yang memiliki informasi atau data tersebut. Data sekunder diperoleh dari dokumen, seperti jurnal, internet, media sosial, dan sumber lain yang terkait dengan penelitian. Internet dan media sosial yang membahas mengenai penelitian terkait juga digunakan sebagai data penunjang.

Penelitian ini menggunakan teknik purposive sampling untuk 
Corinna, et al/ Jurnal Ekonomi Syariah Teori dan Terapan Vol. 6 No. 2 Februari 2019: 319-330; POLA PERILAKU KONSUMSI GENERASI MILLENIAL TERHADAP PRODUK FASHION PERSPEKTIF MONZER KAHF : STUDI KASUS MAHASISWI UNIVERSITAS AIRLANGGA

mendapatkan infoman. Menurut Anshori dan Iswati (2009: 15), purposive sampling adalah teknik penentuan sampel dengan pertimbangan tertentu.

\section{Teknik Pengumpulan Data}

Dalam teknik lapangan, peneliti menggunakan metode-metode sebagai berikut:

a) Wawancara

Dengan wawancara, peneliti dapat menggali sedalamdalamnya data yang ada pada subjek penelitian dan pertanyaan yang diajukan dapat bersifat bebas dan fleksibel namun tetap harus relevan dengan penelitian.

b) Observasi

Metode observasi merupakan teknik pengumpulan data yang mengharuskan peneliti turun ke lapangan dan mengamati hal-hal yang berkaitan dengan subjek penelitian. Tetapi tidak semua perlu diamati oleh peneliti, hanya hal yang relevan dengan data yang dibutuhkan. Peneliti hanya mengamati interaksi sosial yang mereka ciptakan, baik dengan sesama subjek penelitian maupun dengan pihak luar (Patilima, 2007). Dengan observasi, peneliti akan lebih mamppu memahami konteks data secara holistik.

C)Dokumentasi

Dokumen merupakan catatan peristiwa yang sudah berlalu. Dokumen dapat dipahami sebagai setiap catatan tertulis yang berhubungan dengan suatu peristiwa masa lalu, baik yang dipersiapkan maupun tidak dipersiapkan untuk suatu penelitian (Ghony, 2017). Dokumen bisa berbentuk foto, catatan, tulisan, atau karya monumental dari seseorang (Sugiyono, 2011).

\section{Teknik Analisis Data}

Penelitian ini menggunakan teknik analisis data interaktif Miles dan Huberman. Model ini terdiri dari tiga hal utama yaitu :

1. Reduksi data

Reduksi data dapat diartikan sebagai merangkum dan memilih hal-hal pokok dan krusial. Data yang direduksi akan memberikan gambaran yang jelas dan mempermudah peneliti untuk melakukan pengumpulan data selanjutnya. Pada penelitian ini, hasil wawancara yang dari informan diperoleh dengan menggunakan alat rekam Data yang ada diseleksi untuk dipilih yang relevan dengan penelitian.

2. Penyajian data

Penyajian data bertujuan untuk mempermudah memahami hasil penelitian yang bisa diuraikan dalam narasi, bagan, dan sejenisnya.

3. Penarikan kesimpulan/verifikasi Verifikasi adalah langkah terakhir dalam teknik ini. Setelah 
melakukan reduksi dan penyajian data, peneliti mengkaji temuan penelitian kemudian melaporkan hasil penelitian secara lengkap dengan temuan baru yang telah dirumuskan peneliti.

\section{Teknik Keabsahan Data}

Untuk menetapkan keabsahan data diperlukan teknik pemeriksaan. Pelaksanaan teknik pemeriksaan didasarkan atas sejumlah kriteria tertentu. Moleong menyebutkan ada empat kriteria yang digunakan, yaitu :

1. Derajat Kepercayaan (credibility)

Kriteria ini berfungsi untuk melaksanakan penyelidikan sedemikian rupa sehingga tingkat kepercayaan penemuannya dapat dicapai. Adapun cara yang diupayakan agar kebenaran hasil penelitian dapat dipercaya antara lain dengan triangulasi.

Triangulasi adalah teknik pemeriksaan keabsahan data yang memanfaatkan sesuatu yang lain di luar data itu untuk keperluan pengecekan atau sebagai pembanding terhadap data itu (Moleong, 2012: 330). Triangulasi yang dipakai dalam penelitian ini adalah triangulasi sumber yang membandingkan dan mengecek balik derajat kepercayaan suatu informasi yang diperoleh melalui waktu dan alat yang berbeda dalam metode kualitatif (Patton dalam Moleong , $2012: 331$

2. Keteralihan (Transferability)

Nilai transfer berkenaan dengan pernyataan, sehingga hasil penelitian dapat diterapkan atau digunakan dalam situasi lain. Oleh karena itu agar pembaca dapat memahami hasil penelitian kualitatif sehingga ada kemungkinan untuk menerapkan hasil penelitian tersebut, maka dalam membuat laporan, peneliti harus memberikan uraian, rincian, jelas, sistematis, dan dapat dipercaya.

3. Kebergantungan (Dependability)

Dalam penelitian kualitatif, uji kebergantungan dilakukan dengan cara melakukan pemeriksaan terhadap keseluruhan proses penelitian. Peneliti harus diuji kebergantungannya dengan mengecek serta memastikan hasil penelitian benar atau salah.

4. Kepastian (Confirmability)

Dalam penelitian kualitatif, uji kepastian mirip dengan uji kebergantungan sehingga pengujiannya dapat dilakukan secara bersamaan. Menguji kepastian berarti menguji hasil penelitian, dikaitkan dengan proses dalam penelitian. Kepastian yang dimaksud berasal dari konsep objektivitas, sehingga dengan hasil penelitian yang disepakati maka hasil penelitian tidak lagi subjektif, tetapi sudah objektif.

\section{HASIL DAN PEMBAHASAN}

\section{Pembahasan}

Universitas Airlangga merupakan salah satu universitas ternama yang ada di kota Surabaya. Dimana kebanyakan mahasiswa nya berasal dari kota metropolitan yang satu ini. Universitas Airlangga awalnya berdiri pada tahun 1928 dibawah naungan Belanda. Namun , diresmikan pada tahun 1954. Kampus ini memiliki visi misi yang cukup unik dengan 
Corinna, et al/ Jurnal Ekonomi Syariah Teori dan Terapan Vol. 6 No. 2 Februari 2019: 319-330; POLA PERILAKU KONSUMSI GENERASI MILLENIAL TERHADAP PRODUK FASHION PERSPEKTIF MONZER KAHF : STUDI KASUS MAHASISWI UNIVERSITAS AIRLANGGA

membentuk mahasiswa dengan karakter excellent with morality.

Dengan memakai beberapa informan terpilih atas dasar latar belakang dan kebiasaan yang berbeda-beda. Informan pertama adalah LI dimana ia baru saja mengalami kebangkrutan atas usaha kedua orang tuanya dan LI harus banting tulang untuk membiayai keempat adiknya. LI adalah mahasiswa akhir jurusan Ekonomi Islam. LI bekerja menjadi pekerja part time di Texas Chicken Surabaya dan merangkap menjadi supir Grab Bike. Informan kedua adalah SA, SA adalah mahasiswa semester tiga di jurusan Sistem Informasi. SA memiliki latar belakang perekonomian yang berkecukupan lantaran kedua orang tua nya memenuhi kebutuhan bulanannya. SA aktif di berbagai organisasi sebagai kegiatan sehari-hari. Informan ketiga adalah RN, mahasiswa aktif semester lima jurusan Ekonomi Islam. RN adalah perantau dari Sidoarjo yang harus kos di daerah Gubeng Kertajaya. Penggemar skincare yang satu ini selalu meluangkan waktunya untuk hang out bersama teman-temannya. Informan keempat adalah CN, mahasiswa akhir di Fakultas Psikologi yang merupakan aktivis muslim. CN merupakan aktivis di SKI dan BLM, serta menjadi volunteer di sebuah yayasan sosial. $\mathrm{CN}$ sudah mampu memenuhi kebutuhannya termasuk membayar UKT sendiri sejak semester tiga. Dan memiliki tabungan jangka panjang untuk sekolah pasca sarjana nya tahun depan. Informan lima adalah RA, mahasiswa co ass Fakultas Kedokteran Gigi yang menghabiskan banyak waktunya untuk mengurus pasienpasiennya. RA jarang sekali hang out karena ketika weekend, ia akan menemani ibunya. Kemudian proses triangulasi dilakukan pada orang terdekat dari para informan, seperti ibunya, adiknya dan sahabatnya. Dari latar belakang dan kegiatan yang berbedabeda, maka tentunya mereka memiliki konsumsi akan produk fashion yang berbeda pula. Sehingga, hal itu perlu diteliti lebih lanjut.

\section{Pola Perilaku Konsumsi Terhadap Produk Fashion Perspektif Monzer Kahf}

Monzer Kahf memiliki empat prinsip dalam melakukan konsumsi diantaranya adalah

\section{Rasionalisme Konsumsi Islam}

$\begin{array}{ccc}\text { Rasionalisme } & \text { konsumsi } & \text { islam } \\ \text { merupakan suatu } & \text { prinsip yang }\end{array}$
menekankan pada konsistensi konsumsi berdasarkan moral islam memakai akal sehat yang diberikan oleh Allah kepada setiap individu.

Prinsip ini juga mencakup tiga hal yaitu konsep keberhasilan, skala waktu, dan konsep harta. Semua informan sudah menerapkan ketiga cakupan tersebut dimana konsep keberhasilan informan terlihat saat informan mengutamakan kehalalan suatu produk dan yang sesuai syariah. Skala waktu ditunjukkan saat informan lebih mengutamakan ibadah daripada belanja produk fashion. Konsep harta ditunjukkan bahwa semua informan 
Corinna, et al/ Jurnal Ekonomi Syariah Teori dan Terapan Vol. 6 No. 2 Februari 2019: 319-330; POLA PERILAKU KONSUMSI GENERASI MILLENIAL TERHADAP PRODUK FASHION PERSPEKTIF MONZER KAHF : STUDI KASUS MAHASISWI UNIVERSITAS AIRLANGGA

percaya apabila semua harta yang dimiliki hanya titipan dari Allah.

\section{Keseimbangan Konsumsi}

Dalam perekonomian, diperlukan adanya keseimbangan konsumsi antara dunia dan akhirat. Hal ini dapat dilakukan dengan melakukan alokasi kebajikan , tabungan dan investasi, dan konsumsi. Semua informan selalu mengalokasikan pendapatannya untuk tetap infaq , sedekah, dan menabung. Namun, ada sebagian kecil informan yang belum memiliki investasi. Informan juga mengkonsumsi produk fashion sesuai kebutuhan saja.

\section{Konsep Islam Tentang Barang}

Dalam konsep islam, barang adalah bahan-bahan konsumsi yang berguna dan baik manfaatnya. Allah merupakan pemberi nikmat dan pemasok semua kebutuhan untuk umatnya. Barang yang baik dalam islam adalah yang menunjukkan kebaikan dan tidak najis. Serta pemanfaatannya dipakai dengan benar.

Semua informan menganggap trendsetter bukanlah hal utama yang membuat mereka memutuskan untuk mengkonsumsi produk fashion. Produk fashion hanyalah penunjang penampilan belaka, bukan sebagai hal utama dalam berkonsumsi.

\section{Etika Konsumsi Islam}

Islam mengajarkan bahwa dalam memperoleh rejeki harus dengan cara yang halal. Islam menganjurkan untuk menghindari perolehan rejeki secara haram yaitu mencuri, berjudi, mengandung MABGHRIB, dll. Karena, apabila kita mendapatkan dengan cara yang tidak halal, sehalal apapun barang yang kita konsumsi akan menjadi haram.

Semua informan tidak pernah mendapatkan sumber dana dengan cara halal. Mereka juga senantiasa menghindari israf dan tabzir.

\section{v. SIMPULAN DAN SARAN}

\section{Simpulan}

Berdasarkan hasil penelitian yang dilakukan sehingga dapat disimpulkan bahwa :

1. Prinsip rasionalisme konsumsi islam mampu menjadi tumpuan dari prinsipprinsip lainnya. Mengkonsumsi produk fashion yang berlabel halal dan sesuai dengan syariah masih menjadi prioritas. Tak lupa untuk mengingat ibadah sholat walaupun sedang berada di dalam Mall , hal ini menunjukkan bahwa masih mengingat Allah di segala sisi. Serta mempercayai bahwa segala sesuatu yang kita miliki hanya titipan dari Allah.

2. Prinsip keseimbangan konsumsi juga terlaksana dengan baik. Menyisihkan sebagian harta kita untuk hal-hal berguna harus dilakukan. Seperti infaq, sedekah, menabung dan berinvestasi

3. Prinsip konsep islam tentang barang terutama pemaknaan individu terhadap produk fashion masih sesuai dengan kajian teori Monzer Kahf, trendsetter bukanlah hal utama yang mempengaruhi individu untuk mengkonsumsi produk fashion. Senantiasa mengkonsumsi hanya sesuai kebutuhan, agar terhindar pula dari riya. 
Corinna, et al/ Jurnal Ekonomi Syariah Teori dan Terapan Vol. 6 No. 2 Februari 2019: 319-330; POLA PERILAKU KONSUMSI GENERASI MILLENIAL TERHADAP PRODUK FASHION PERSPEKTIF MONZER KAHF : STUDI KASUS MAHASISWI UNIVERSITAS AIRLANGGA

4. Prinsip etika konsumsi islam juga masih sesuai dengan nilai-nilai islam. Memperoleh rejeki dengan cara yang halal, mengindari tabzir dan israf juga masih dilakukan.

\section{Saran}

1. Bagi informan, dengan adanya penelitian ini diharap mampu menjadi evaluasi dan control diri dalam mengkonsumsi produk fashion. Diharapkan agar informan tidak terjebak ke arus globalisasi karena produk-produk fashion branded sedang marak-maraknya masuk ke kota ini.

2. Bagi peneliti selanjutnya, diharapkan penelitian ini bisa menjadi pedoman dan acuan yang bermanfaat ke depannya. Diharapkan ada penelitian lebih lanjut mengenai konsumsi generasi millennial terhadap produk fashion di kota lain, kampus lain atau berdasarkan latar belakang yang lebih beragam.

\section{DAFTAR PUSTAKA}

Al Arif, M. Nur Rianto \& Amalia, Euis. 2010. Teori Mikroekonomi: Suatu Perbandingan Ekonomi Islam dan Ekonomi Konvensional. Jakarta: Kencana.

Rahardja, P \& Manurung, M. 2008. Teori Ekonomi Makro. Edisi 4. Jakarta: Fakultas Ekonomi Universitas Indonesia.

Dagun, Save M. (1992). Pengantar Filsafat Ekonomi. Jakarta: Rineka Cipta.

Engel, James F. dkk. Perilaku Konsumen. (Edisi keenam Jilid 1). (Penerjemah: F.X Budiyanto). Jakarta: Binapura Aksara.
Walter Nicholson, Microeconomic Theory; Basic, Principles and Extensions (Ohio: Thomson Corporation, 2005), 69-70.

Suparmoko, Pengantar Ekonomika Mikro .Yogyakarta: BPFE-YOGYAKARTA. 1998

Nugroho J. Setiadi, Perilaku Konsumen Konsep dan Implikasi untuk Strategi dan Penelitian Pemasaran. Jakarta: Kencana. 2005

M. Nur Rianto al-Arif dan Euis Amalia, Teori Mikroekonomi; Suatu Perbandingan Ekonomi Islam dan Ekonomi Konvensional . Jakarta: Kencana. 2010

Suprayitno, Eko. Ekonomi Mikro Prespektif Islam. Malang : Sukses Offset. 2008

Sudarsono, Heri. Konsep Ekonomi Islam. Yogyakarta : Ekonisia. 2007

Muhammad Nejatullah Siddiqi, The Economic Enterprise, diterjemah oleh Anas Sidik, Kegiatan Ekonomi dalam Islam (Cet. ke2; Jakarta: Bumi Aksara, 1996), h. 95.

Yusuf Qardhawi, Dawr al-Qiyam wa al-Akhlāq fī alIqtișad al-Islāmin, diterjemah oleh Zainal Arifin dan Dahlia Husim, Norma dan Etika Ekonomi Islam, (Cet.ke-4; Jakarta:Gema InsaniPress, 1422H./2001 M.), h.352.

Boudrillard, Jean L. 2011. Masyarakat Konsumsi, terjemahan Wahyunto. Bantul: Kreasi Wacana.

Jauhar ,Ahmad Al-Mursi Husain. Maqashid Syariah, Jakarta:Amzah,2010.

Ahmad Qorib, Ushul Fikih 2, (Jakarta: PT. Nimas Multima, 1997), Cet, II), hlm. 170. 
Corinna, et al/ Jurnal Ekonomi Syariah Teori dan Terapan Vol. 6 No. 2 Februari 2019: 319-330; POLA PERILAKU KONSUMSI GENERASI MILLENIAL TERHADAP PRODUK FASHION PERSPEKTIF MONZER KAHF : STUDI KASUS MAHASISWI UNIVERSITAS AIRLANGGA

M.Umer Chapra.Masa Depan IImu Ekonomi Sebuah Tinjauan Islam.(Tazkia Cendekia. 2001), HIm 102.

Karim, Adiwarman Azwar. Ekonomi Mikro Islam. Jakarta : IITI . 2004.

Kahf, Monzer. Ekonomi Islam : Telaah Analitik Terhadap Fungsi dan Sistem Ekonomi Islam. Terjemahan Machnul Husein. Yogyakarta : Pustaka Pelajar. 1995.

Siddiqi, Muhammad Nejatullah. Kegiatan Ekonomi Dalam Islam. Terj. Anas Sidik. Jakarta : PT Bumi Aksara. 2004.

Sukirno, Sadono. Pengantar Teori Ekonomi Mikro. Jakarta : Raja grafindo Persada. 2002

Khan, Muhammad Fahim. Essays In Islamic Economics. United Kingdom : The Islamic Foundation. 1995.

Moleong, Lexy.J. Metode Penelitian Kualitatif, (edisi : revisi). Bandung : PT Remaja Rosda Karya. 2006.

Sugiyono. Metode Penelitian Kuantitatif Kualitatif dan R\&D. Bandung: CV Alfabeta. 2010

Arikunto, Suharsimi. 2005. Dasar-Dasar Evaluasi Pendidikan. Jakarta: Bumi Aksara.

Patilima, Hamid. 2007. Metode Penelitian Kualitatif. Jakarta: Alfabeta.

Miles, MattHew B.Miles dan A. Michael Huberman. 2007. Analisis Data Kualitatif Buku Sumber tentang Metode-Metode Baru. Terjemahan Tjetjep Rohendi Rohisi. Jakarta: Universitas Indonesia.
Harsono. 2008. Model-Model Pengelolaan Perguruan Tinggi. Yogyakarta: Pustaka Pelajar.

Sutama. 2010. Metode Penelitian Pendidikan. Cetakan pertama. Surakarta: Fairuz Media.

Yin, Robert K, 2008, Studi Kasus (Desain Dan Metode), (Case Study Research Design and Methods") diterjemahkan oleh Drs. M. Djauzi Mudzakir, MA, PT.Raja Grafindo Persada,Jakarta 